\title{
A Correlative Study of Intra Ocular Pressure, Mean Arterial Pressure and CSF Pressure in Non Neurological Patients
}

\author{
Pragati Garg ${ }^{*}$, Smriti Diwedi, Ritika Mullick \\ Department of Ophthalmology, Era's Lucknow Medical College and Hospital, Lucknow, India \\ Email address: \\ pragati89@gmail.com (P. Garg),smidi007@gmail.com (S. Diwedi), ritikamullick@yahoo.co.in (R. Mullick) \\ ${ }^{*}$ Corresponding author
}

To cite this article:

Pragati Garg, Smriti Diwedi, Ritika Mullick. A Correlative Study of Intra Ocular Pressure, Mean Arterial Pressure and CSF Pressure in Non Neurological Patients. International Journal of Ophthalmology \& Visual Science. Vol. 3, No. 2, 2018, pp. $32-38$.

doi: $10.11648 /$ j.ijovs.20180302.14

Received: August 24, 2018; Accepted: September 11, 2018; Published: October 15, 2018

\begin{abstract}
Introduction: Blood pressure is one of the most important and most widely studied factors affecting the IOP. Another important factor that plays an important role in pathogenesis of glaucoma is cerebrospinal fluid pressure. The present study was planned to study the relationship between intraocular pressure, mean arterial pressure and estimated Cerebrospinal fluid pressure in non-neurological patients. Material and Method: The present study was conducted in the Department of Ophthalmology. The study was carried out as a case-control study for 18 months. The patients above 40 years of age irrespective of sex were included in the study after their informed consent. Total of 250 patients were taken out of which 150 were cases with signs of glaucoma and 100 were controls with no signs of glaucoma. Result: 250 subjects enrolled in the study, a total of $150(60 \%)$ were clinically established cases of glaucoma (with IOP $>22 \mathrm{mmHg}$ ) and comprised the case group of study whereas remaining 100 were apparently healthy subjects with no signs and symptoms of glaucoma and had IOP $<22$ $\mathrm{mmHg}$ and comprised the control group of the study. Mean ICP values of subjects with IOP $31-40 \mathrm{~mm} \mathrm{Hg}$ were significantly higher as compared to those with IOP $23-30 \mathrm{~mm} \mathrm{Hg}$ and $\leq 22 \mathrm{mmHg}$ respectively ( $\mathrm{p}=0.002$ ). Mean Arterial Pressure (MAP) showed a significant near mild positive correlation with IOP $(\mathrm{r}=0.288 ; \mathrm{p}<0.001)$ and a moderate positive correlation with ICP $(\mathrm{r}=0.520 ; \mathrm{p}<0.001)$. However, the correlation between IOP and ICP was weak positive but significant $(\mathrm{p}=0.010)$. The relationship between gender and mean MAP and IOP and ICP was evaluated, and the values of all of them were higher in males as compared to females, but the difference was significant only for mean IOP and ICP ( $p=0.180$ and $p<0.001$ respectively). Conclusion: The findings in present study thus indicate that the relationship between IOP, ICP and MAP is governed by a multitude of factors (in present study these covariates were age, gender and BMI). The present study was unique in the sense that it was probably the first Indian study exploring relationship between IOP, MAP and ICP, and that too in healthy individuals.
\end{abstract}

Keywords: Intra Ocular Pressure, Mean Arterial Pressure, Cerebrospinal Fluid Pressure, Non-Neurological Patients

\section{Introduction}

The relationship between intraocular pressure and glaucoma is widely established, so much so that increased intraocular pressure has been included as a major risk factor and sometimes one of the essential components in diagnosis of glaucoma [1, 2, 3]. Permanent loss of vision in glaucoma occurs due to the damage to the optic nerve, contributed by the increased intraocular pressure.

The IOP is the resultant of the pressures, or volumes, of aqueous humor, vitreous body, and blood vessels within the globe [4]. The anatomical and pathological causes that influence the intraocular pressure include intraglobal changes viz. aqueous humor volume, blood volume, foreign bodies, tumors, hemorrhage, vitreous humor volume and scleral rigidity and extraglobal changes, viz., anesthetic regional blocks, extraocular compression devices, extraocular muscle tone, sclera strapping, retrobulbar or peribulbar hematoma, abscess or tumor, face mask or prone position [5] some other factors such as smoking [6], older age [7], gender [6, 7], blood pressure $[6,7,8]$, family history of glaucoma $[6,7]$, 
pulse rate $[6,7]$, diabetes (elevated glycosylated hemoglobin) [6, 7], myopia [9], alcohol usage [6], race (African) [8], nuclear sclerosis $[7,9]$, body mass index (BMI) $[6,7,8]$ and iris color [9] also affect the intraocular pressure.

Among these factors, blood pressure is one of the most important and most widely studied factors affecting the IOP. Intraocular pressure (IOP) has been found to be associated with systemic blood pressure levels in population based studies [7, 10-20].

Studies in the past have shown that apart from IOP, which is considered to be a major risk factor for glaucoma, another important factor that plays an important role in pathogenesis of glaucoma is cerebrospinal fluid pressure.

Some recent studies have suggested a physiologic correlation between cerebrospinal fluid pressure (CSFP), systemic blood pressure and intraocular pressure (IOP) [2124]. Thus, there is interplay of systemic blood pressure, intraocular pressure and cerebrospinal fluid pressure in affecting each other as well as resulting in the development of glaucoma.

The existence of relationship between intraocular pressure, systemic blood pressure and CSF pressure could not be examined for a long period owing to the fact that exact measurement of CSF pressure is possible only through lumbar puncture using invasive techniques. Owing to this limitation, the initial work on exploring this relationship was limited among neurological patients requiring lumbar puncture for various diagnostic/therapeutic purposes but there were limited or almost no studies exploring this relationship amongst the individuals without neurological diseases. However, in the recent years, some mathematical models have been prepared that help in assessing CSF pressure without requiring an invasive measurement [24]. This advancement has helped in providing a basis for evaluation of this relationship in individuals without neurological disorder too.

Hence, the present study was planned to study the relationship between intraocular pressure, mean arterial pressure and estimated Cerebrospinal fluid pressure in nonneurological patients.

\section{Material and Method}

The present study was conducted in the Department of Ophthalmology at Era's Lucknow Medical College and Hospital, Lucknow. The study was carried out as a casecontrol study for 18 months.

The patients above 40 years of age irrespective of sex were included in the study after their informed consent. Total of 250 patients were taken out of which 150 were cases with signs of glaucoma and 100 were controls with no signs of glaucoma. The sample size was calculated at $95 \%$ confidence and $80 \%$ power.

Any patient with history of intraocular surgeries, ocular disease, any intracranial or spinal cord disease, intake of drugs like mannitol, carbonic anhydrase inhibitors, $\beta$ blockers or history of alcohol intake which can directly or indirectly influence IOP or CSF pressure were excluded from the study.

In all the included subjects' demographic details and medical history was noted. A detailed history about the ocular symptoms, if any and various factors which can influence IOP were recorded on a preset proforma. A detailed history of signs and symptoms of Open angle glaucoma, family history of glaucoma and history of any medicine intake that influences intraocular pressure and intracranial pressure was taken.

All the patients were subjected to a thorough systemic and local examination. Hemodynamic parameters were noted (pulse rate, DBP, SBP, MAP). Height and weight of patients was measured to calculate body mass index (BMI).

Thorough ocular evaluation was done on all selected patients both clinically as well as with the help of diagnostic instruments. Visual acuity was tested using Snellen's charts; anterior segment evaluation was done using diffuse torch light and slit lamp examination. Direct ophthalmoscope was used to carry out fundus examination. Indirect ophthalmoscopy was also performed to visualize the fundus up to periphery. For good depth perception examination under $+90 \mathrm{D}$ lens was performed. IOP.

Goldmann applanation tonometer was done to measure the

As the assessment was done in normal healthy patients having no neurological disorder hence invasive technique (lumbar puncture) to measure CSF pressure was ruled out owing to ethical considerations. Hence a non-invasive calculation method was used as described by Wang et al. [25]

CSF pressure $[\mathrm{mm} \mathrm{Hg}]=0.44$ Body Mass Index $\left[\mathrm{kg} / \mathrm{m}^{2}\right]+$ 0.16 diastolic blood pressure [ $\mathrm{mm} \mathrm{Hg}$ ] $-0.18 \mathrm{x}$ Age [years].

The data has been represented as frequencies and percentages. Data was analyzed using Statistical Package for Social Sciences, version 15.0. To seek the association between different variables, Chi-square test, independent samples ' $t$ '-test and ANOVA were used to find out significant associations. Pearson correlation coefficient was calculated to measure the extent of correlation. The confidence level of the study was kept at 95\%, hence a "p" value less than 0.05 indicated a statistically significant association.

\section{Result}

Out of 250 subjects enrolled in the study, a total of 150 $(60 \%)$ were clinically established cases of glaucoma (with IOP $>22 \mathrm{mmHg}$ ) and comprised the case group of study whereas remaining 100 were apparently healthy subjects with no signs and symptoms of glaucoma and had IOP $<22 \mathrm{mmHg}$ and comprised the control group of the study.

Age of subjects in the study ranged from 42 to 69 years. Mean age of cases and controls was 52.03 \pm 6.58 and $51.84 \pm 6.17$ years respectively. Maximum numbers of patients in both the groups were aged 41-50 years. Statistically, the age of both the groups was matched. Majority of subjects were males $(72.4 \%)$. There were 42 
(28.67\%) females in case group and $26(26 \%)$ females in control group. Statistically, this difference was not significant.

Proportion of overweight subjects was $68.67 \%$ in cases and $77 \%$ in controls. However, the difference between two groups was not significant statistically.

Mean systemic blood pressure indicators i.e. (SBP, DBP and MAP) were 127.60 and 128.44, 80.04 and 80.28, 95.97 and 96.44 respectively in cases and controls and thus showing no significant difference between the two groups.

Overall IOP ranged from 17.3 to $37.8 \mathrm{mmHg}$. All the controls had IOP $\leq 22 \mathrm{mmHg}$. In cases IOP values ranged from 22.4 to $37.8 \mathrm{mmHg}$.

Mean IOP was $27.07 \pm 4.30 \mathrm{mmHg}$ in cases as compared to $19.10 \pm 1.36 \mathrm{mmHg}$ in controls.

Table 1. Association between IOP and MAP.

\begin{tabular}{|c|c|c|c|c|c|c|c|c|c|c|}
\hline \multirow{2}{*}{ Group } & & \multicolumn{3}{|c|}{ Overall } & \multicolumn{3}{|c|}{ Cases } & \multicolumn{3}{|c|}{ Controls } \\
\hline & & $\mathbf{N}$ & Mean IOP & SD & $\mathbf{N}$ & Mean IOP & SD & $\mathbf{N}$ & Mean IOP & SD \\
\hline Subjects with MAP<90 mmHg & & 43 & 22.43 & 3.58 & 26 & 25.02 & 1.54 & 17 & 18.46 & 1.52 \\
\hline Subjects with MAP $>90 \mathrm{mmHg}$ & & 207 & 24.16 & 5.43 & 124 & 27.47 & 4.57 & 83 & 19.23 & 1.30 \\
\hline \multirow{2}{*}{ Statistical significance } & ' $t$ ' & \multirow{2}{*}{\multicolumn{3}{|c|}{$\begin{array}{l}2.00 \\
0.046\end{array}$}} & 2.69 & \\
\hline & 'p' & & & & 0.008 & & & \multicolumn{3}{|c|}{0.032} \\
\hline
\end{tabular}

$\mathrm{OR}=1.02 ;(\mathrm{CI} 95 \%: 0.523-2.004)$

Table 2. Association between MAP and ICP.

\begin{tabular}{|c|c|c|c|c|c|c|c|c|c|c|}
\hline \multirow{2}{*}{ Group } & & \multicolumn{3}{|c|}{ Overall } & \multicolumn{3}{|c|}{ Cases } & \multicolumn{3}{|c|}{ Controls } \\
\hline & & $\mathbf{N}$ & Mean ICP & SD & $\mathbf{N}$ & Mean ICP & SD & $\mathbf{N}$ & Mean ICP & SD \\
\hline Subjects with $\mathrm{MAP}<90 \mathrm{mmHg}$ & & 43 & 13.66 & 0.92 & 26 & 13.56 & 0.93 & 17 & 13.82 & 0.92 \\
\hline Subjects with MAP $>90 \mathrm{mmHg}$ & & 207 & 14.79 & 1.78 & 124 & 14.88 & 1.84 & 83 & 14.65 & 1.69 \\
\hline \multirow{2}{*}{ Statistical significance } & ' $\mathrm{t}$ ' & \multicolumn{3}{|c|}{4.035} & \multicolumn{3}{|c|}{3.561} & \multicolumn{3}{|c|}{1.969} \\
\hline & 'p' & \multicolumn{3}{|c|}{$<0.001$} & \multicolumn{3}{|c|}{$<0.001$} & \multicolumn{3}{|c|}{0.052} \\
\hline
\end{tabular}

In both the cases as well as controls independently and also on overall assessment mean IOP, and mean ICP values were higher among subjects with MAP $>90 \mathrm{mmHg}$ as compared to those having MAP $<90 \mathrm{mmHg}$. But the odds of MAP $>90 \mathrm{mmHg}$ were to using (OR=1.02) thus no significant difference was seen between the two groups.

Table 3. Association between IOP and ICP.

\begin{tabular}{llll}
\hline \multirow{2}{*}{ IOP Range } & Mean ICP & & \\
\cline { 2 - 4 } & N & Mean & SD \\
\hline$\leq 22 \mathrm{~mm} \mathrm{Hg}$ & 100 & 14.51 & 1.61 \\
$23-30 \mathrm{~mm} \mathrm{Hg}$ & 119 & 14.41 & 1.86 \\
$31-40 \mathrm{~mm} \mathrm{Hg}$ & 31 & 15.59 & 1.04 \\
\hline
\end{tabular}

\section{$\mathrm{F}=6.338 ; \mathrm{p}=0.002$}

On looking for association between IOP and ICP, we found that mean ICP values of subjects with IOP $31-40 \mathrm{~mm}$ Hg were significantly higher as compared to those with IOP $23-30 \mathrm{~mm} \mathrm{Hg}$ and $\leq 22 \mathrm{mmHg}$ respectively ( $\mathrm{p}=0.002$ ).

Table 4. Bivariate Correlation between IOP, MAP and ICP.

\begin{tabular}{llll}
\hline SN & Correlation factors & 'r' & 'p' \\
\hline 1. & IOP vs MAP & 0.288 & $<0.001$ \\
2. & IOP vs ICP & 0.163 & 0.010 \\
3. & MAP vs ICP & 0.520 & $<0.001$ \\
\hline
\end{tabular}

MAP showed a significant near mild positive correlation with IOP $(\mathrm{r}=0.288$; $\mathrm{p}<0.001)$ and a moderate positive correlation with $\mathrm{ICP}(\mathrm{r}=0.520$; $\mathrm{p}<0.001)$. However, the correlation between IOP and ICP was weak positive but significant $(\mathrm{p}=0.010)$.

Table 5. Multivariate regression analysis for IOP as a dependent variable on independent variables ICP and MAP.

\begin{tabular}{lllll}
\hline \multirow{2}{*}{ Variable } & \multicolumn{2}{l}{ Unstandardized Coefficients } & \multicolumn{2}{l}{ Standardized Coefficients } \\
\cline { 2 - 3 } & B & Std. Error & Beta & \\
\hline (Constant) & 3.255 & 4.380 & & .743 \\
CSF Pressure & .053 & .216 & .017 & .458 \\
MAP & .206 & .053 & .279 & 0.807 \\
\hline
\end{tabular}

$\mathrm{r}^{2}=0.289$

In a multivariate model where IOP was placed as the dependent variable on independent variables CSF pressure and MAP, only MAP was found to be significantly associated with IOP while the CSF pressure did not show a significant association with IOP. The $\mathrm{r}^{2}$ value was 0.289 which indicated that variances in MAP and IOP can explain variances in ICP to the extent of 
nearly $28.9 \%$.

ASSOCIATION OF DIFFERENT STUDY VARIABLES WITH DEMOGRAPHIC VARIABLES

Table 6. Association of MAP, IOP and ICP with different demographic and anthropometric variables.

\begin{tabular}{|c|c|c|c|c|c|c|c|}
\hline & \multirow{2}{*}{$\mathbf{N}$} & \multicolumn{2}{|c|}{ Mean MAP } & \multicolumn{2}{|l|}{ IOP } & \multicolumn{2}{|l|}{ ICP } \\
\hline & & Mean & SD & Mean & SD & Mean & SD \\
\hline \multicolumn{8}{|l|}{ Age } \\
\hline 41-50 Years & 120 & 92.79 & 6.08 & 22.47 & 3.21 & 14.98 & 1.66 \\
\hline 51-60 Years & 99 & 100.62 & 6.62 & 25.55 & 6.73 & 14.75 & 1.39 \\
\hline $61-70$ Years & 31 & $\begin{array}{l}94.92 \\
F=46.7\end{array}$ & $\mathrm{~F}=46.77 ; \mathrm{p}<0.001$ & \multicolumn{2}{|c|}{$\mathrm{F}=10.286 ; \mathrm{p}<0.001$} & $\begin{array}{l}12.59 \\
F=30.4\end{array}$ & $\mathrm{~F}=30.42 ; \mathrm{p}<0.001$ \\
\hline \multicolumn{8}{|l|}{ Gender } \\
\hline Male & 181 & \multicolumn{2}{|c|}{$F=1.807 ; p=0.180$} & \multicolumn{2}{|c|}{$\mathrm{F}=5.185 ; \mathrm{p}=0.024$} & \multicolumn{2}{|c|}{$\mathrm{F}=21.048 ; \mathrm{p}<0.001$} \\
\hline BMI & & & & & & & \\
\hline Normal weight & 70 & 94.08 & 3.56 & 23.42 & 3.65 & 13.03 & 1.48 \\
\hline Overweight & 180 & \multicolumn{2}{|c|}{$F=8.733 ; p=0.003$} & \multicolumn{2}{|c|}{$\mathrm{F}=0.697 ; \mathrm{p}=0.405$} & $\begin{array}{l}15.20 \\
\mathrm{~F}=118 .\end{array}$ & 1.39 \\
\hline
\end{tabular}

Mean MAP levels and mean IOP were maximum among those aged 51-60 years and minimum among those aged 4150 years. Statistically, a significant association was observed between age and mean MAP levels $(p<0.001)$ and also between age and mean IOP levels $(\mathrm{p}<0.001)$ while mean ICP levels showed a significant decline with increasing age.

The demographic and anthropometric associations despite showing a similar trend indicated the multivariability of ICP and hence we proposed a new multivariate model in which ICP was considered as dependent on MAP, IOP, Age, BMI and Gender $(\mathrm{M}=1, \mathrm{~F}=2)$.

On looking for relationship between gender and mean MAP and IOP and ICP, it was found that the values of all of them were higher in males as compared to females but the difference was significant only for mean IOP and ICP ( $\mathrm{p}=0.180$ and $\mathrm{p}<0.001$ respectively).

Mean of MAP, IOP and ICP were all higher in obese patients as compared to normal patients with $\mathrm{p}$ values of $0.003, \mathrm{p}=0.405, \mathrm{p}<0.001$ respectively.

Table 7. Expanded Multivariate Model with ICP as a dependent variable on independent variables MAP, IOP, Gender, Age and BMI.

\begin{tabular}{|c|c|c|c|c|c|}
\hline \multirow{2}{*}{ Variable } & \multicolumn{2}{|c|}{ Unstandardized Coefficients } & \multirow{2}{*}{$\begin{array}{l}\text { Standardized Coefficients } \\
\text { Beta }\end{array}$} & \multirow{2}{*}{$\mathbf{t}$} & \multirow{2}{*}{ Sig. } \\
\hline & B & Std. Error & & & \\
\hline (Constant) & 2.617 & 1.237 & & 2.115 & 0.035 \\
\hline MAP & .150 & .010 & .616 & 14.832 & $<0.001$ \\
\hline IOP & .016 & .012 & .050 & 1.365 & 0.173 \\
\hline Gender $[\mathrm{M}=1 ; \mathrm{F}=2)$ & -.530 & .144 & -.138 & -3.669 & $<0.001$ \\
\hline Age & -.149 & .011 & -.555 & -14.026 & $<0.001$ \\
\hline BMI & .215 & .039 & .231 & 5.519 & $<0.001$ \\
\hline
\end{tabular}

$\mathrm{R}^{2}=0.844$

In the expanded model where ICP was a dependent variable on independent variables MAP, IOP, Gender, Age and BMI, all the independent variables except IOP showed a significant association with ICP. The $\mathrm{r}^{2}$ value was 0.844 , thus showing that variances in independent variables were able to explain variances in dependent variable to the extent of $84.4 \%$. Thus, showing that the expanded model had a better applicability as compared to the brief multivariate model (with IOP and MAP as independent variables) tested earlier.

\section{Discussion}

Measurement of systemic blood pressure and intraocular pressure can be performed using non-invasive technologies yet same is not possible for measurement of intracranial/cerebrovascular pressure. Keeping in view the relationship of systemic blood pressure with the organ specific pressure gradients in general and that of intraocular pressure in particular, it might be possible that a mathematical predictive model for estimation of CSF/intracranial pressure could be developed. In present study, we were trying to articulate one such model for projection of CSF/intracranial pressure with the help of intraocular pressure and systemic blood pressure.

Selection of non-neurological patients was done purposely as measurement of CSF pressure among these patients was really challenging. For study, a non-invasive CSF pressure calculation technique was used as proposed by Wong et al. [25].

The study was thus targeted towards establishing a relationship between intraocular pressure, systemic blood pressure and CSF/intracranial pressure in a case-control study distinguished by categorical differences in IOP and as such giving a wider scope for establishing a categorical to linear or categorical to categorical relationship.

No significant difference between cases and controls was 
observed with respect to age, gender, BMI and blood pressure measurements. This in turn seemed to dilute our hypothesis that IOP is dependent on systemic blood pressure as matching of age, gender, BMI and blood pressure between cases and controls while at the one hand ruled out confounding effect of these variables while at the same time also ruled out their effect as a risk factor for rise in IOP which was categorically increased in cases as compared to controls.

Mean IOP levels of cases and controls were $27.07 \pm 4.30$ $\mathrm{mmHg}$ and $19.10 \pm 1.36 \mathrm{mmHg}$ respectively. The IOP levels of subjects in two groups were distinctly differentiated as IOP was the criteria for differentiation between cases and controls.

However, on evaluating CSF pressure difference between two groups, the difference was not found to be significant thus indicating that pattern of IOP levels and CSF pressure in two groups did not show a similar trend, that is CSF pressure was independent of glaucomatous status as such and IOP levels as an extension. On evaluating this relationship further the correlation of IOP with CSF was found to be weak $(\mathrm{r}=0.163 ; \mathrm{p}=0.010)$. This finding defies the proposition made by Berdahl (2009) [26] who proposed that CSF pressure may hold the key to understanding why IOP plays a major role in the development of glaucoma.

The findings in present study do not endorse this view point. There are two grounds for this - first, the association proposed by Berdahl (2009) [26] was proposed as a cause rather than effect as studied in present study, secondly the empiricity of Berdahl (2009) [26] hypothesis failed to be clinically proven in several studies. There is quite disagreement regarding existence of an association between glaucoma/increased IOP and increased CSF pressure/ICP. Table 8 below summarizes the direction of relationship of glaucoma/IOP with CSF/intracranial pressure as observed in different clinical studies:

Table 8. Direction of relationship of glaucoma/IOP with CSF/intracranial pressure as observed in different clinical studies.

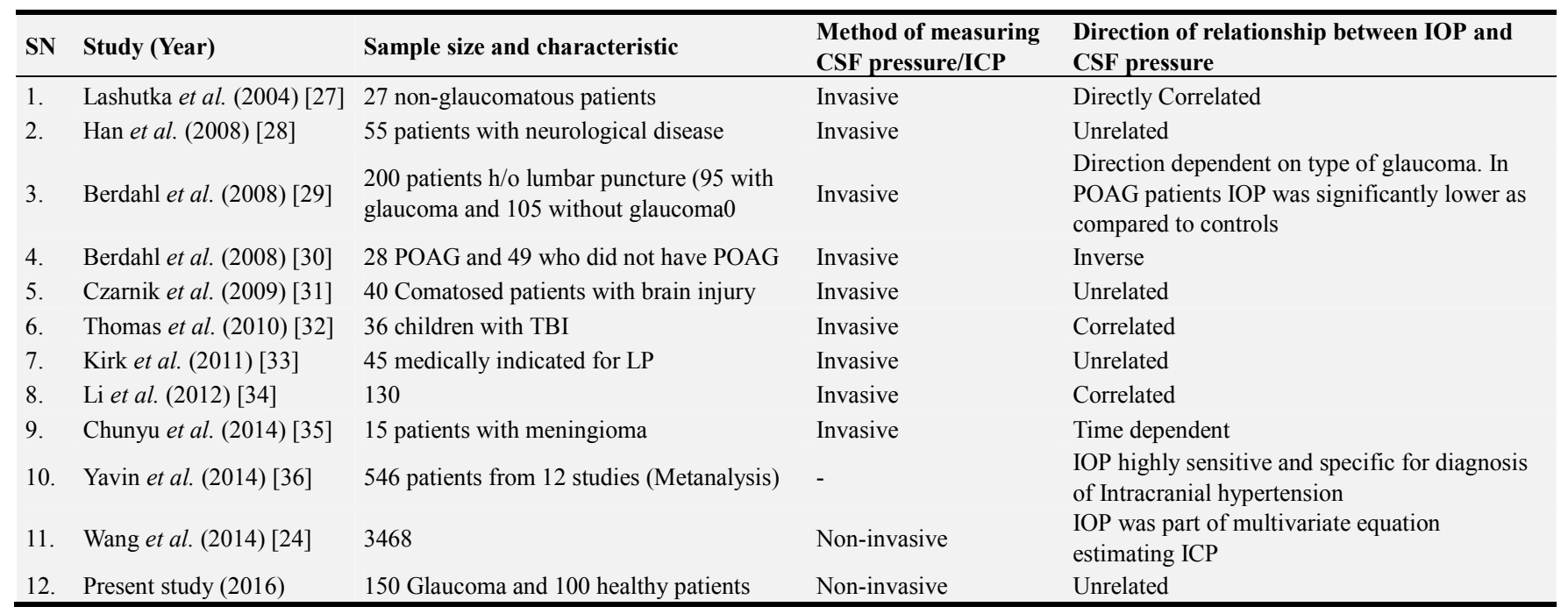

An overview of Table 8 above shows that out of 12 studies cited above, only 3 indicated a direct correlation between IOP and CSF Pressure/ICP, 1 indicated an inverse correlation and 3 proposed non-existence of a correlation. Remaining 5 studies showed a partial and covariate dependent relationship between IOP and CSF pressure/ICP. The variance in results of these studies might be attributable to the variation in study designs, patient profile and time and method of measurement of IOP and ICP. As such, the conflicting results in different studies show lack of a direct correlation between the two and showed that this relationship is dependent on other variables too.

Although, the present study did not find a significant association between IOP and CSF pressure/ICP, however, the present study found a significant association between Mean arterial pressure and ICP. For both case group as well as control groups separately or for overall combined assessment of both the groups, mean ICP values of subjects with MAP $<90 \mathrm{mmHg}$ were significantly lower as compared to those having MAP $>90 \mathrm{mmHg}$. An association between IOP and MAP was also observed on overall combined assessment and in case group respectively. On evaluating the linearity of correlation, a moderate positive correlation between MAP and ICP and a near mild positive correlation between IOP and MAP was observed.

Thus, MAP was found to be more proximally correlated with both ICP as well as IOP. A number of studies have endorsed this relationship. There are studies that have reported a consistent relationship between IOP and blood pressure with each $10 \mathrm{~mm} \mathrm{Hg}$ increment in SBP leading to a mean $0.23-0.31 \mathrm{~mm} \mathrm{Hg}$ rise in IOP [17, 37, 38-40]. In other studies, though no such mathematical relationship was suggested, however, intraocular pressure was correlated positively with systemic blood pressure [13, 42, 43, 44]. In present study we obtained a near mild positive correlation between IOP and MAP. Sithole et al. (2009) 45 on the other hand found a moderate positive correlation of IOP with SBP and MAP. In present study, the targeted goal was to show the relationship of IOP, ICP and MAP, and this exploration was being done primarily to come up with a non-invasive measurement procedure for CSF pressure/ICP. 
Hence a linear regression model was proposed in which IOP was kept as a dependent variable on independent variables CSF pressure and MAP. The linear regression model showed that only MAP had a significant association with the outcome and as such the model had a low explanatory value $(\mathrm{r} 2=0.289)$.

These findings indicated a possible role of other covariates. Multivariability of IOP and ICP dependence has been suggested in several previous studies too [46, 47]. In present study too, we tried to analyze a multivariate relationship of MAP, IOP and ICP.

Using age, gender, BMI, MAP and IOP as predictors, the multivariate linear regression showed a significant association of ICP with MAP, Gender, Age and BMI. The model had an excellent explanatory ability $(\mathrm{r} 2=0.844)$.

The findings in present study thus indicate that the relationship between IOP, ICP and MAP is governed by a multitude of factors (in present study these covariates were age, gender and BMI). The present study failed to generate a relationship between IOP and CSF pressure/ICP; however, the present study showed that MAP was the major determinant of both IOP as well as ICP. Despite absence of a linear correlation between IOP and ICP, the present study indicated that both are influenced by a common factor (MAP) and owing to this coincidence, in some studies the relationship between IOP and ICP has been studied. The present study was unique in the sense that it was probably the first Indian study exploring relationship between IOP, MAP and ICP, and that too in healthy individuals. One of the limitations of present study was that it used a calculated ICP estimation model. However, the usefulness of present study lies in the fact that it provided a multivariate linear regression model which could be used for calculating ICP noninvasively. The accuracy of the model needs to be validated against invasive measurements, for this a further study in suitable set of patients where invasive ICP measurements are feasible is recommended.

\section{Conclusion}

The findings in present study thus indicate that the relationship between IOP, ICP and MAP is governed by a multitude of factors (in present study these covariates were age, gender and BMI). The present study failed to generate a relationship between IOP and CSF pressure/ICP; however, the present study showed that MAP was the major determinant of both IOP as well as ICP. The present study was unique in the sense that it was probably the first Indian study exploring relationship between IOP, MAP and ICP, and that too in healthy individuals.

\section{References}

[1] Foster PJ, Buhrmann R, Quigley HA, Johnson GJ. The definition and classification of glaucoma in prevalence surveys. The British Journal of Ophthalmology. 2002; 86 (2):238-242.
[2] Fleischman D, Allingham RR. The role of cerebrospinal fluid pressure in glaucoma and other ophthalmic diseases: A review. Saudi Journal of Ophthalmology. 2013; 27 (2):97-106.

[3] Bonomi L, Marchini G, Marraffa M, Bernardi P, De Franco I, Perfetti S, et al. Prevalence of glaucoma and intraocular pressure distribution in a defined population. The EgnaNeumarkt Study. Ophthalmology. 1998; 105 (2):209-215.

[4] MacDiarmid IR, Holloway KB. Factors affecting Intraocular Pressure. Proc R Soc Med. 1976 Aug; 69 (8): 601-602.

[5] Murgatroyd H, Bembridge J. Intraocular pressure. Contin Educ Anaesth Crit Care Pain 2008; 8 (3): 100-103.

[6] Wu SY, Leske MC. Associations with intraocular pressure in the Barbados Eye Study. Arch Ophthalmol 1997; 115 (12): $1572-1576$.

[7] Klein BE, Klein R, Linton KL. Intraocular pressure in an American community. The Beaver Dam Eye Study. Invest Ophthalmol Vis Sci 1992; 33 (7): 2224-2228.

[8] Bulpitt CJ, Hodes C, Everitt MG. Intraocular pressure and systemic blood pressure in the elderly. Br J Ophthalmol 1975; 59 (12): 717-720.

[9] Weih LM, Mukesh BN, McCarty CA, Taylor HR. Association of demographic, familial, medical, and ocular factors with intraocular pressure. Arch Ophthalmol 2001; 119 (6): 875880 .

[10] Bengtsson B. Some factors affecting the distribution of intraocular pressures in a population. Acta Ophthalmol (Copenh) 1972; 50:33-46.

[11] Bulpitt CJ, Hodes C, Everitt MG. Intraocular pressure and systemic blood pressure in the elderly. Br J Ophthalmol 1975; 59:717-20.

[12] Kahn HA, Leibowitz HM, Ganley JP, et al. The Framingham Eye Study. II. Association of ophthalmic pathology with single variables previously measured in the Framingham Heart Study. Am J Epidemiol 1977; 106: 33-41.

[13] Klein BE, Klein R. Intraocular pressure and cardiovascular risk variables. Arch Ophthalmol 1981; 99:837-9.

[14] McLeod SD, West SK, Quigley HA, Fozard JL. A longitudinal study of the relationship between intraocular and blood pressures. Invest Ophthalmol Vis Sci. 1990; 31:23612366 .

[15] Wu SY, Leske MC. Associations with intraocular pressure in the Barbados Eye Study. Arch Ophthalmol 1997; 115:1572-6.

[16] Tielsch JM, Katz J, Sommer A, Quigley HA, Javitt JC. Hypertension, perfusion pressure, and primary open-angle glaucoma. A population-based assessment. Arch Ophthalmol 1995; 113:216-21.

[17] Dielemans I, Vingerling JR, Algra D, Hofman A, Grobbee DE, de Jong PT. Primary open-angle glaucoma, intraocular pressure, and systemic blood pressure in the general elderly population. The Rotterdam Study. Ophthalmology 1995; 102:54-60.

[18] Healey PR, Mitchell P, Smith W, et al. The influence of age and intraocular pressure on the optic cup in a normal population. J Glaucoma 1997; 6:274-8. 
[19] Mitchell P, Lee AJ, Wang JJ, Rochtchina E. Intraocular pressure over the clinical range of blood pressure: blue mountains eye study findings. Am J Ophthalmol 2005; 140: $131-132$.

[20] Foster PJ, Machin D, Wong TY, et al. Determinants of intraocular pressure and its association with glaucomatous optic neuropathy in Chinese Singaporeans: the Tanjong Pagar Study. Invest Ophthalmol Vis Sci 2003; 44:3885-91.

[21] Ren R, Jonas JB, Tian G, Zhen Y, Ma K, Li S, Wang H, Li B, Zhang X, Wang N. Cerebrospinal fluid pressure in glaucoma. A prospective study. Ophthalmology 2010; 117: 259-266.

[22] Ren R, Wang N, Zhang X, Tian G, Jonas JB. Cerebrospinal fluid pressure correlated with body mass index. Graefes Arch Clin Exp Ophthalmol 2012; 250: 445- 446.

[23] Xie XB, Zhang XJ, Fu J, Wang H, Jonas JB, Peng X, Tian G, Xian J, Ritch R, Li L, Kang Z, Zhang S, Yang D, Wang N; Beijing iCOP Study Group. Intracranial pressure estimation by orbital subarachnoid space measurement. Crit Care 2013; 17: R162.

[24] Wang YX, Jonas JB, Wang N, You QS, Yang D, Xie XB, Xu L. Intraocular Pressure and Estimated Cerebrospinal Fluid Pressure. The Beijing Eye Study 2011. PLoS ONE 2014; 9 (8): e104267.

[25] Wong TT, Wong TY, Foster PJ, Crowston JG, Fong CW, Aung T. The Relationship of Intraocular Pressure with Age, Systolic Blood Pressure, and Central Corneal Thickness in an Asian Population. Investigative Ophthalmology \& Visual Science September 2009; Vol. 50: 4097-4102. doi:10.1167/iovs.082822 .

[26] Berdahl J. Cerebrospinal Fluid Pressure and Glaucoma. Glaucoma Today 2009; 14-18. Lashutka MK, Chandra A, Murray HN, Phillips GS, Hiestand BC. The relationship of intraocular pressure to intracranial pressure. Ann Emerg Med. 2004 May; 43 (5):585-91.

[27] Han Y, McCulley TJ, Horton JC. No correlation between intraocular pressure and intracranial pressure. Ann Neurol. 2008 Aug; 64 (2):221-4. doi: 10.1002/ana.21416.

[28] Berdahl JP, Fautsch MP, Stinnett SS, Allingham RR. Intracranial pressure in primary open angle glaucoma, normal tension glaucoma, and ocular hypertension: a case-control study. Invest Ophthalmol Vis Sci. 2008; 49 (12):5412-5418.

[29] Berdahl JP, Allingham RR, Johnson DH. Cerebrospinal fluid pressure is decreased in primary open angle glaucoma. Ophthalmology. 2008; 115 (5):763-768.

[30] Czarnik T, Gawda R, Kolodziej W, Latka D, Sznajd-Weron K, Weron R. Associations between intracranial pressure, intraocular pressure and mean arterial pressure in patients with traumatic and non-traumatic brain injuries. Injury, Int. J. Care Injured 40 (2009) 33-39.

[31] Thomas S, Jared H, Andrea P and Edward C. Correlation of intraocular pressure with intracranial pressure in children with severe head injuries. Pediatric Critical Care Medicine. Sept 2010; 11 (5): 593-598.
[32] Kirk T, Jones K, Miller S, Corbett J. Measurement of intraocular and intracranial pressure: Is there a relationship? Annals of Neurology 2011; 70 (2): 323-326.

[33] Li Z, Yang Y, Lu Y, Liu D, Xu E, Jia J, Yang D, Zhang X, Yang $\mathrm{H}$, Ma $\mathrm{D}$ and Wang $\mathrm{N}$. Intraocular pressure vs intracranial pressure in disease conditions: A prospective cohort study (Beijing iCOP study). BMC Neurology BMC series 2012; 66: 1-4.

[34] Chunyu T, Xiujun P, Li N, Qin L and Tian Z. The correlation between intracranial pressure and intraocular pressure after brain surgery, Int J Ophthalmol Eye Res, 2014; 2 (5), 54-58.

[35] Yavin D, Luu J, James MT, Roberts DJ, Sutherland GR, Jette N, Wiebe S. Diagnostic accuracy of intraocular pressure measurement for the detection of raised intracranial pressure: meta-analysis: a systematic review. J Neurosurg. 2014 Sep; 121 (3):680-1687.

[36] Wu S-Y, Leske CM. Associations with intraocular pressure in the Barbados Eye Study. Arch Ophthalmol 1997; 115:15721576 .

[37] Nalano T, Tatemichi M, Miura Y, Sugita M, et al. Long-term physiologic changes of intraocular pressure: A 10-year longitudinal analysis in young and middle aged Japanese men. Ophthalmology 2005; 112:609-616.

[38] Tielsch J, Katz J, Sommer A, et al. Hypertension, perfusion pressure and primary open angle glaucoma. A population based assessment. Arch Ophthalmol 1995; 113:216-221.

[39] Bonomi L, Marchini G, Marraffa M, et al. Vascular risk factors for primary open angle glaucoma. The Egna-Neumarkt Study. Ophthalmology 2000; 107:1287-1293.

[40] Leske MC, Podgor MJ. Intraocular pressure, cardiovascular risk variables, and visual field defects. Am J Epidemiol. 1983 Aug; 118 (2):280-7.

[41] Lee JS, Choi YR, Lee JE, Choi HY, Lee SH, Oum BS. Relationship Between Intraocular pressure and Systemic Health Parameters in the Korean Population. Korean J Ophthalmol. 2002; 16: 13-19.

[42] Klein BEK, Klein R, Knudtson MD. Intraocular pressure and systemic blood pressure: longitudinal perspective: the Beaver Dam Eye Study. Br J Ophthalmol 2005; 89:284-287. doi: 10.1136/bjo.2004.048710.

[43] Nirmala N, Adhilakshmi A, Harshila Jain, Karthika Priyadarshini U. A comparative study of intraocular pressure changes in postmenopausal normotensive and hypertensive women. Int J Res Med Sci. 2014; 2 (3): 876-880.

[44] Hulsman CA, Vingerling JR, Hofman A, et al. Blood pressure, arterial stiffness and open angle glaucoma. The Rotterdam Study. Arch Ophthalmol 2007; 125:805-12.

[45] Wang YX, Jonas JB, Wang N, You QS, Yang D, Xie XB, Xu L. Intraocular Pressure and Estimated Cerebrospinal Fluid Pressure. The Beijing Eye Study 2011. PLoS ONE 2014; 9 (8): e104267.

[46] Berdahl JP, Allingham RR, Johnson DH. Cerebrospinal fluid pressure is decreased in primary open angle glaucoma. Ophthalmology. 2008; 115 (5):763-768. 